\title{
Orthopedic treatment, complications, and cost analysis of 67 soldiers injured in a three-month period
}

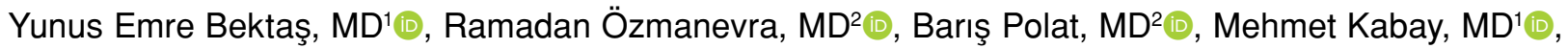 \\ Nihat Demirhan Demirkıran, $\mathrm{MD}, \mathrm{PhD}^{3}$ (D) \\ ${ }^{1}$ Department of Orthopedics and Traumatology, Kilis State Hospital, Kilis, Turkey \\ ${ }^{2}$ Department of Orthopedics and Traumatology, University of Kyrenia, Faculty of Medicine, Kyrenia, Cyprus \\ ${ }^{3}$ Department of Orthopedics and Traumatology, Kütahya Health Sciences University, Kütahya, Turkey
}

Wars are still ongoing across the world even after the Second World War. Countries are obliged to address the significant costs incurred as a result of injuries caused to soldiers and civilians in wars. Extremity injuries are frequently encountered in trauma patients with access to war surgeons. This was the case in many countries, such as Iran, Afghanistan, and Syria. ${ }^{[1-4]}$ Wounds caused by high-energy army weapons are complex and contaminated. ${ }^{[5]}$

A civil war arose in Syria in 2011 and is still ongoing. Due to the civil war in the country, a large number of patients has been admitted to hospitals in the border cities of Turkey. A significant amount of patients who has been injured by war are taken to Kilis district hospitals across the border with Turkey. The level II trauma center at Kilis State Hospital is $8.4 \mathrm{~km}$ away from the Syrian border. The number of soldiers and civilian patients injured in the war in Syria and treated in this center reached around 2000 in the previous year. Although comparatively more civilians have been injured in this war, higher morbidity and mortality rates have been observed among injured soldiers who have been brought from the battlefield.

Received: October 14, 2019

Accepted: December 03, 2019

Published online: March 02, 2020

Correspondence: Ramadan Özmanevra, MD. Dr. Suat Günsel Girne Üniversitesi Hastanesi, Ortopedi ve Travmatoloji Kliniği, Karakum, 99320 Girne, Kuzey Kıbrıs.

E-mail: rozmanevra@gmail.com

Doi: $10.5606 /$ ehc. 2020.71808

Citation: Bektaș YE, Özmanevra R, Polat B, Kabay M, Demirkıran ND. Orthopedic treatment, complications, and cost analysis of 67 soldiers injured in a three-month period. Jt Dis Relat Surg 2020;31(1):102-108

\section{ABSTRACT}

Objectives: This study aims to analyze the musculoskeletal injury types, injury mechanisms, treatment modalities, complications, and costs of 67 consecutive soldiers wounded in the battlefield in Syria civil war over a period of three months.

Patients and methods: This retrospective study was conducted between January 2018 and March 2018 at Kilis State Hospital. The study included 67 male patients (median age 28.5 years; range, 15 to 46 years). Patients' ages, injury mechanisms, fracture types, fracture locations, injury severity scores, mangled extremity severity scores, complications, and treatment costs were evaluated.

Results: Twenty-three patients were injured due to handmade explosives, 21 patients due to gunshots, 16 patients due to landmines, five patients due to rockets, and two patients due to grenades. A total of $35.8 \%$ of the patients $(n=24)$ had concomitant trauma. The mean hospitalization period was 10.2 days (range, 1-45 days). A total of 88 treatments were performed on these patients. Thirty-six of these treatments were external fixators, 21 were amputations, 12 were open reduction internal fixations, seven were closed reduction internal fixations, five were intramedullary nailings, three were cannulated screws, three were fasciotomies, and one was an arthrodesis. The treatment costs ranged from 1,577 to 296,286 Turkish Liras. Complications were observed in 17 patients and 11 of them developed infections, three of them had compartment syndrome, and three died during the hospitalization period.

Conclusion: The increase in warfare technology is correlated with the severity of military injuries in the battlefields. These injuries still lead to high traumatic amputation rates, high-risk complications, and high costs.

Keywords: Cost, open fracture, surgery, Syrian, war.

In this study, we aimed to analyze the musculoskeletal injury types, injury mechanisms, treatment modalities, complications, and costs of 67 consecutive soldiers wounded in the battlefield in Syria civil war over a period of three months. 


\section{PATIENTS AND METHODS}

This retrospective study was conducted at Kilis State Hospital between January 2018 and March 2018 involving 67 consecutive male patients (median age 28.5 years; range, 15 to 46 years) treated for extremity injuries. Data were collected from the patients' and hospital's medical records including demographics, injury mechanisms, injury locations and sides, time from field to hospital, mangled extremity severity score (MESS), injury severity score (ISS), Gustilo-Anderson classification, hospitalization periods, costs, complications, and the presence of accompanying traumas. The study protocol was approved by the University of Kyrenia Ethics Committee (2019/ 01-001). A written informed consent was obtained from each patient. The study was conducted in accordance with the principles of the Declaration of Helsinki.

The demographic characteristics of the subgroups with lower or upper extremity injuries, with complications or infection, and with an ISS value of 14 and below or above 14 were compared statistically.

\section{Statistical analysis}

The statistical analysis was carried out using IBM SPSS version 22.0 software (IBM Corp., Armonk, NY, USA). Mean, standard deviation, lowest and highest median, frequency, and ratio values were used as the descriptive statistics of the data. The distribution of variables was measured using the KolmogorovSmirnov test. The Mann-Whitney U test was used for the analysis of quantitative independent data. The chi-square test was used for the analysis of qualitative independent data, and the Fischer's exact test was used when the chi-square test conditions were not met. A $p$ value $<0.05$ was considered statistically significant.

\section{RESULTS}

The mean time from injury to hospitalization was 3.8 hours (range, 1 to 10 hours). The injury mechanisms, injury locations, and treatment modalities are presented in Tables I and II. For skin defects in the extremities, four patients underwent full-thickness skin grafting, four patients underwent rotational flap, and two patients underwent free flap through plastic and reconstructive surgery.

When the injured regions were evaluated in terms of lower and upper extremities, lower extremity injuries were found in 51 patients, upper extremity injuries in 11 patients, and both lower and upper extremity injuries in five patients (Figure 1 and 2). According to the Gustilo-Anderson classification, 38 patients $(56.7 \%)$ had grade $3 a$ fractures, 12 patients (17.9\%) had grade $3 \mathrm{~b}$ fractures, and 17 patients $(25.4 \%)$ had grade $3 \mathrm{c}$ fractures. The mean hospitalization period was 10.2 days (range, 1 to 45 days). The treatment cost ranged from 1,577 to 296,286 Turkish Liras (TL) (Table II). A total of $35.8 \%$ of the patients $(n=24)$ had concomitant trauma. While $30.4 \%$ of lower extremity injuries were associated with accompanying traumas, this rate was $63.6 \%$ for upper extremity injuries. These accompanying traumas are presented in Table III.

The age of the patients in the lower and upper extremity groups did not differ significantly $(p=0.436)$. Mangled extremity severity score and ISS values were significantly higher in the lower extremity group than in the upper extremity group $(p=0.008, p=0.019)$. Furthermore, the rate of accompanying trauma was significantly higher

\begin{tabular}{|c|c|c|c|c|c|c|}
\hline & ationship b & veen injury & $\begin{array}{l}\text { BLE I } \\
\text { chanisms and treatme }\end{array}$ & odality & & \\
\hline Treatment type & Grenade & Gunshot & Handmade explosive & Landmine & Rocket & Total \\
\hline & $\mathrm{n}$ & $\mathrm{n}$ & $\mathrm{n}$ & $\mathrm{n}$ & $\mathrm{n}$ & $\mathrm{n}$ \\
\hline External fixator & 2 & 15 & 10 & 5 & 4 & 36 \\
\hline Open reduction internal fixation & 2 & 4 & 4 & 1 & 1 & 12 \\
\hline Closed reduction internal fixation & - & 2 & 5 & - & - & 7 \\
\hline Intramedullary nail & - & 3 & - & 2 & - & 5 \\
\hline Cannulated screw & - & - & 2 & 1 & - & 3 \\
\hline Fasciotomy & - & - & 2 & - & 1 & 3 \\
\hline Amputation & - & - & 5 & 16 & - & 21 \\
\hline Arthrodesis & - & - & - & - & 1 & 1 \\
\hline Total & 4 & 24 & 28 & 25 & 7 & 88 \\
\hline
\end{tabular}


in the upper extremity group than in the lower extremity group $(p=0.035)$ (Table IV). The length of hospital stay was significantly higher in the group with complications than in the group without complications $(p=0.022)$. The rate of accompanying trauma was not significant $(p=0.263)$ in the groups with and without complications.

Gustilo-Anderson classification did not differ significantly in the groups with and without complications $(\mathrm{p}=0.352)($ Table $\mathrm{V})$. The age, cost, length of hospital stay, and Gustilo-Anderson classification were significantly higher in the infection group than the non-infection group $(\mathrm{p}<0.05)$. The rate of comorbid trauma was not significant $(p=0.157)$ in the groups with and without infection. Mangled extremity severity score, the rate of comorbid trauma, and Gustilo-Anderson classification were significantly higher in ISS $>14$ group than ISS $\leq 14$ group $(\mathrm{p}<0.05)$.

Complications were observed in 17 patients and 11 of them had infections. Infection was a complication in $16.4 \%$ of all patients. Fasciotomy was

\begin{tabular}{|c|c|c|c|c|c|}
\hline \multicolumn{6}{|c|}{$\begin{array}{c}\text { TABLE II } \\
\text { Patients' demographics }\end{array}$} \\
\hline & $\mathrm{n}$ & $\%$ & Mean $\pm S D$ & Median & Min-Max \\
\hline Age (year) & & & $28.5 \pm 7.7$ & 27.0 & $15-46$ \\
\hline \multicolumn{6}{|l|}{ Gender } \\
\hline Male & 67 & 100.0 & & & \\
\hline Female & 0 & 0 & & & \\
\hline Time from injury to hospitalization (hour) & & & $3.8 \pm 1.5$ & 4.0 & $1-10$ \\
\hline Mangled extremity severity score & & & $5.7 \pm 2.6$ & 6.0 & $2-11$ \\
\hline Injury severity score & & & $16.7 \pm 12.8$ & 13.0 & $4-57$ \\
\hline Cost (TL) & & & $15,065 \pm 35,555$ & 9,138 & $1,577-296,286$ \\
\hline Hospitalization period (day) & & & $10.2 \pm 8.3$ & 8.0 & $1-45$ \\
\hline \multicolumn{6}{|l|}{ Injury mechanism } \\
\hline Grenade & 2 & 3.0 & & & \\
\hline Gunshot & 21 & 31.3 & & & \\
\hline Handmade explosive & 23 & 34.3 & & & \\
\hline Landmine & 16 & 23.9 & & & \\
\hline Rocket & 5 & 7.5 & & & \\
\hline \multicolumn{6}{|l|}{ Side } \\
\hline Left & 23 & 34.3 & & & \\
\hline Right & 33 & 49.3 & & & \\
\hline Right and left & 11 & 16.4 & & & \\
\hline \multicolumn{6}{|l|}{ Injury location } \\
\hline Lower extremity & 51 & 76.1 & & & \\
\hline Upper extremity & 11 & 16.4 & & & \\
\hline Upper extremity and lower extremity & 5 & 7.5 & & & \\
\hline \multicolumn{6}{|l|}{ Complications } \\
\hline$(-)$ & 50 & 74.6 & & & \\
\hline$(+)$ & 17 & 25.4 & & & \\
\hline Compartment syndrome & 3 & 4.5 & & & \\
\hline Exitus & 3 & 4.5 & & & \\
\hline Infection & 11 & 16.4 & & & \\
\hline \multicolumn{6}{|l|}{ Gustilo-Anderson classification } \\
\hline 3a & 38 & 56.7 & & & \\
\hline $3 b$ & 12 & 17.9 & & & \\
\hline $3 c$ & 17 & 25.4 & & & \\
\hline \multicolumn{6}{|l|}{ Accompanying trauma } \\
\hline$(-)$ & 43 & 64.2 & & & \\
\hline $\mathrm{H}_{2}$ & 24 & 35.8 & & & \\
\hline
\end{tabular}




\begin{tabular}{|lcc|}
\multicolumn{3}{|c|}{ TABLE III } \\
Detailed analysis of accompanying traumas \\
\hline Accompanying trauma & Upper extremity & Lower extremity \\
\cline { 2 - 3 } Subdural hematoma & 2 & $\mathrm{n}$ \\
Abdominal trauma & 1 & 2 \\
Eardrum perforation & 1 & 1 \\
Mandibular fracture & - & - \\
Maxillary fracture & - & 1 \\
Hemothorax & - & 1 \\
Pneumothorax & - & 2 \\
Artery injury & 1 & 1 \\
Thermal skin necrosis & 3 & 2 \\
Total & 8 & 9 \\
\hline
\end{tabular}

performed on three patients due to the development of compartment syndrome. One patient died due to hemodynamic instability, one patient died due to thromboembolism, and one patient died due to adult respiratory distress syndrome during the hospitalization period.

\section{DISCUSSION}

The most important finding of our study is that the treatment of soldiers wounded in the battlefield involves high rates of complications and costs. Many articles have been published in Turkey about the civil war in Syria. ${ }^{[4,6,7]}$ However, all of these studies evaluated civilians or refugees affected by the civil war in Syria. The fact that our study only included soldiers wounded on the battlefield in a short period of three months reveals the difference and importance.

In their study, Karakus et al. ${ }^{[7]}$ evaluated the hospital admissions and costs of those injured in the Syrian war where most of the admissions were in orthopedics. The most frequent presenting complaint was gunshot injury. In our study, the rates were close to each other; the most common injury was due to handmade explosive, and the second most common injury was due to gunshot. The sum of these two accounted for $2 / 3$ of all the injuries.

The medical costs incurred by patients transferred from the Syrian border to the hospitals reportedly exceeded US\$150 million by April 2012. ${ }^{[8]}$

\begin{tabular}{|c|c|c|c|c|c|c|c|c|c|}
\hline \multicolumn{10}{|c|}{$\begin{array}{l}\text { TABLE IV } \\
\text { s of subgroups witl }\end{array}$} \\
\hline & \multicolumn{4}{|c|}{ Lower extremity } & \multicolumn{4}{|c|}{ Upper extremity } & \multirow[b]{2}{*}{$p$} \\
\hline & $\mathrm{n}$ & $\%$ & Mean $\pm S D$ & Median & $\mathrm{n}$ & $\%$ & Mean $\pm S D$ & Median & \\
\hline Age (year) & & & $28.9 \pm 8.0$ & 28.0 & & & $26.2 \pm 5.5$ & 24.0 & $0.436^{*}$ \\
\hline $\begin{array}{l}\text { Time from injury to } \\
\text { hospitalization (hour) }\end{array}$ & & & $3.8 \pm 1.5$ & 4.0 & & & $3.5 \pm 1.6$ & 3.0 & $0.490^{*}$ \\
\hline MESS & & & $6.1 \pm 2.7$ & 6.5 & & & $3.7 \pm 0.6$ & 4.0 & $0.008^{*}$ \\
\hline Injury severity score & & & $17.6 \pm 12.1$ & 16.0 & & & $12.0 \pm 15.6$ & 5.0 & $0.019^{*}$ \\
\hline Cost (TL) & & & $15,662 \pm 38,856$ & 8,811 & & & $12,027 \pm 5,253$ & 10638 & $0.294^{*}$ \\
\hline Hospitalization period (day) & & & $10.0 \pm 8.2$ & 8.0 & & & $10.9 \pm 9.0$ & 13.0 & $0.665^{*}$ \\
\hline Accompanying trauma & & & & & & & & & $0.035 \dagger$ \\
\hline$(-)$ & 39 & 69.6 & & & 4 & 36.4 & & & \\
\hline$(+)$ & 17 & 30.4 & & & 7 & 63.6 & & & \\
\hline Gustilo-Anderson classification & & & & & & & & & $0.345 \dagger$ \\
\hline $3 a$ & 31 & 55.4 & & & 7 & 63.6 & & & \\
\hline $3 b$ & 9 & 16.1 & & & 3 & 27.3 & & & \\
\hline $3 c$ & 16 & 28.6 & & & 1 & 9.1 & & & \\
\hline Complications & & & & & & & & & $0.874 \dagger$ \\
\hline$(-)$ & 42 & 75.0 & & & 8 & 72.7 & & & \\
\hline$(+)$ & 14 & 25.0 & & & 3 & 27.3 & & & \\
\hline Infection & & & & & & & & & $0.371 \dagger$ \\
\hline$(-)$ & 48 & 85.7 & & & 8 & 72.7 & & & \\
\hline$(+)$ & 8 & 14.3 & & & 3 & 27.3 & & & \\
\hline
\end{tabular}




\begin{tabular}{|c|c|c|c|c|c|c|c|c|c|}
\hline \multicolumn{10}{|c|}{$\begin{array}{c}\text { TABLE V } \\
\text { f demographic characteristics of sub }\end{array}$} \\
\hline & \multicolumn{4}{|c|}{ Complication (-) } & \multicolumn{4}{|c|}{ Complication (+) } & \multirow[b]{2}{*}{$p$} \\
\hline & $\mathrm{n}$ & $\%$ & Mean $\pm S D$ & Median & $n$ & $\%$ & Mean $\pm S D$ & Median & \\
\hline Age (year) & & & $27.6 \pm 7.3$ & 25.0 & & & $31.1 \pm 8.2$ & 31.0 & $0.112^{*}$ \\
\hline $\begin{array}{l}\text { Time from injury to } \\
\text { hospitalization (hour) }\end{array}$ & & & $3.7 \pm 1.2$ & 4.0 & & & $4.2 \pm 2.2$ & 3.0 & $0.929^{*}$ \\
\hline MESS & & & $5.4 \pm 2.7$ & 4.5 & & & $6.6 \pm 2.3$ & 7.0 & $0.088^{*}$ \\
\hline Injury severity score & & & $15.3 \pm 11.5$ & 12.0 & & & $20.9 \pm 15.5$ & 16.0 & $0.173^{*}$ \\
\hline Cost (TL) & & & $10,153 \pm 5,556$ & 8,745 & & & $29,514 \pm 69,447$ & 11,401 & $0.320^{*}$ \\
\hline Hospitalization period (day) & & & $8.6 \pm 6.5$ & 7.0 & & & $14.8 \pm 11.0$ & 13.0 & $0.022^{*}$ \\
\hline Accompanying trauma & & & & & & & & & $0.263 \dagger$ \\
\hline$(-)$ & 34 & 68.0 & & & 9 & 52.9 & & & \\
\hline$(+)$ & 16 & 32.0 & & & 8 & 47.1 & & & \\
\hline Gustilo-Anderson classification & & & & & & & & & $0.352 \dagger$ \\
\hline $3 a$ & 30 & 60.0 & & & 8 & 47.1 & & & \\
\hline $3 b$ & 7 & 14.0 & & & 5 & 29.4 & & & \\
\hline $3 c$ & 13 & 26.0 & & & 4 & 23.5 & & & \\
\hline
\end{tabular}

In the cost analysis by Karakus et al., ${ }^{[7]}$ the mean cost was 3,723 TL per case (range, 15-69,556 TL). In our study, the mean cost was 9,138 TL (range, 1,577-296,286 TL). The patient who had the costliest treatment died. The treatment cost was probably higher in our study because of the increased use of surgical equipment and invoicing, and the accompanying injuries of the patients were more complicated. The mean hospitalization period was eight days (range, 1-45 days).
In a study by Duramaz et al., ${ }^{[4]} 158$ patients (91 males, 67 females; mean age 39 years) were evaluated in a 34-month period. In this study, lower extremity injuries were higher than upper extremity injuries. The mean hospitalization period was 5.6 days, and the mean treatment cost was 3,844 TL. In our study, the mean hospitalization period was eight days, and the mean treatment cost was 9,138 TL. The reason for the higher hospitalization period and cost may have been the more complicated injuries as it only involved soldiers.
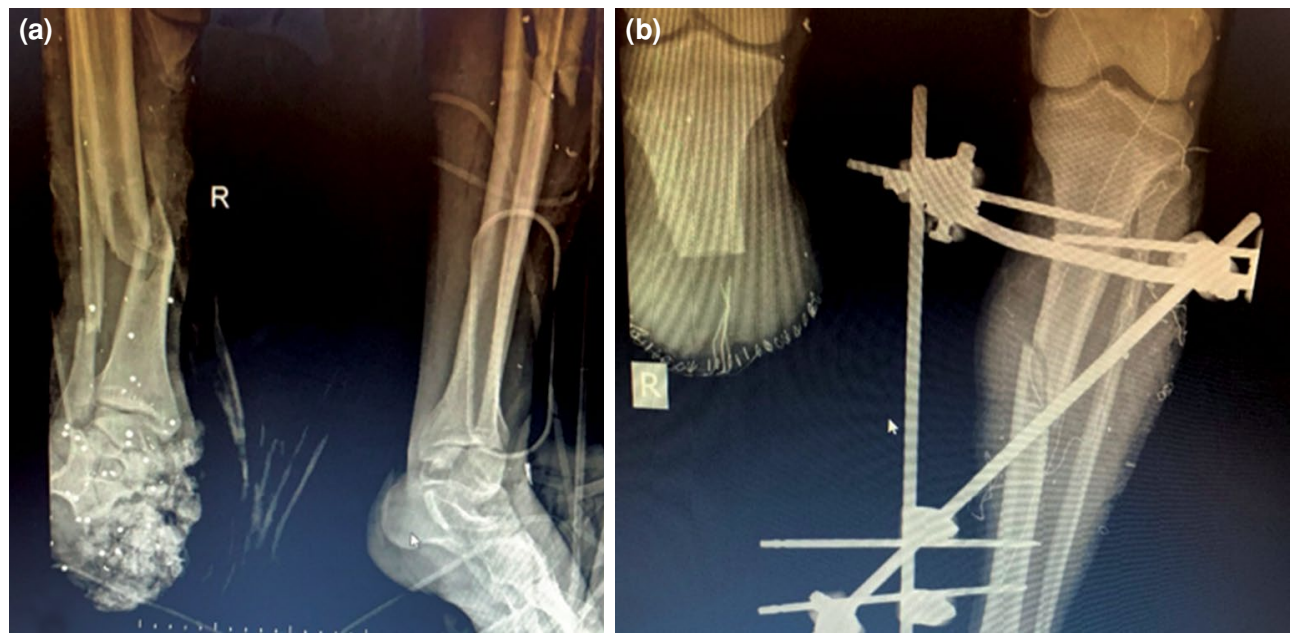

FIGURE 1. (a) Preoperative X-ray of a patient with fractures of both tibias, who was injured due to hand made explosive. (b) Postoperative X-ray of patient; external fixation and below knee amputation were performed simultaneously. 

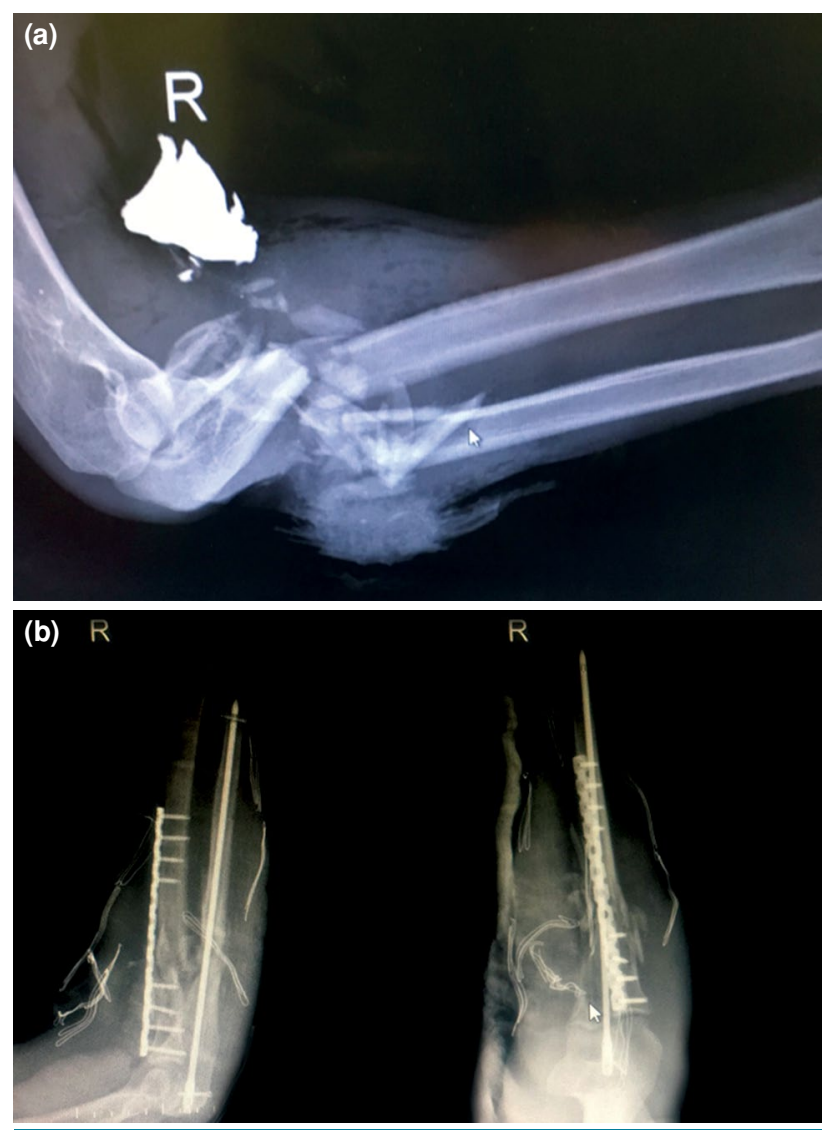

FIGURE 2. (a) Preoperative lateral elbow X-ray of a 41-yearold male patient who was admitted to emergency department due to a grenade injury. (b) Postoperative anteroposterior and lateral elbow X-rays of same patient who underwent open reduction and internal fixation of both bone forearm fractures.

The average age of patients in similar battles in recent years was around 26 years. ${ }^{[9-11]}$ Similarly, the average age of patients in our study was 27 years.

Compared with previous reports dating back to the Second World War, the risk of open injuries to the humerus and forearm appears to be decreased, while the rates of those with lower extremity injuries are slightly elevated. ${ }^{[2,9]}$ Dougherty et al. ${ }^{[12]}$ concluded that the proportions of upper and lower extremity injuries are almost equivalent $(47.3 \%$ and $43.2 \%$, respectively). In our study, upper extremity injuries were approximately $1 / 5$ of lower extremity injuries. Similarly, in the study by Duramaz et al., ${ }^{[4]}$ lower extremity injuries were higher than upper extremity injuries.

Traumatic amputations show a consistent ratio in relation to wars since the advent of modern surgical techniques in the second half of the $20^{\text {th }}$ century ${ }^{[12,13]}$ During the Vietnam war, the amputation rate was estimated to be between $5 \%$ and $8 \%,{ }^{[12]}$ whereas Stansbury et al. ${ }^{[14]}$ documented a major extremity amputation rate of $7 \%$ among all combat casualties with extremity injuries. In our study, amputation accounted for approximately $25 \%$ of all treatments. We think that traumatic amputation is higher since $68.2 \%$ of the injuries were categorized as high-energy injuries, which were caused by handmade explosives, landmines, and rockets. In addition, it is inevitable that this rate would be high as the patients included in the study were brought from the battlefield. ${ }^{[9]}$

In the literature, the use of an external fixator for the initial treatment of open fractures has been well established. ${ }^{[15-19]}$ External fixation allows a simple and rapid intervention to stabilize and prepare the patient for the next step of the treatment. ${ }^{[20]}$ A study by Alhammoud et al. ${ }^{[21]}$ included more patients with Gustilo-Anderson types 1 and 2 rather than type 3 . On the contrary, all the patients were classified as Gustilo-Anderson type 3 in our study. Out of 88 treatments, 36 consisted of external fixators $(40.9 \%)$.

The limitation of this study was that it included a relatively limited number of patients in a retrospective study design. In addition, since the soldiers returned to Syria after being discharged, data for recent follow-up and late complications were not available. Nevertheless, we believe that this is an eligible study to show the high rates of morbidity, mortality, and cost of injuries in the battlefield. ${ }^{[22]}$

In conclusion, registration data of large patient populations with high financial costs, which cannot be reached by the health system due to language restrictions, creates serious health problems. ${ }^{[23]}$ Thus, we believe that the results obtained from this study will contribute valuable information to the literature. Moreover, increased warfare technology correlates with the severity of military injuries in battlefields. These injuries are still associated with high traumatic amputation rates, high-risk complications, and high costs.

\section{Declaration of conflicting interests}

The authors declared no conflicts of interest with respect to the authorship and/or publication of this article.

\section{Funding}

The authors received no financial support for the research and/or authorship of this article.

\section{REFERENCES}

1. Penn-Barwell JG, Roberts SA, Midwinter MJ, Bishop JR. Improved survival in UK combat casualties from Iraq and Afghanistan: 2003-2012. J Trauma Acute Care Surg 2015;78:1014-20. 
2. Owens BD, Kragh JF Jr, Macaitis J, Svoboda SJ, Wenke JC. Characterization of extremity wounds in Operation Iraqi Freedom and Operation Enduring Freedom. J Orthop Trauma 2007;21:254-7.

3. Owens BD, Kragh JF Jr, Wenke JC, Macaitis J, Wade CE, Holcomb JB. Combat wounds in operation Iraqi Freedom and operation Enduring Freedom. J Trauma 2008;64:295-9.

4. Duramaz A, Bilgili MG, Bayram B, Ziroğlu N, Bayrak A, Avkan MC. Orthopedic trauma surgery and hospital cost analysis in refugees; the effect of the Syrian civil War. Int Orthop 2017;41:877-84.

5. Taylor CJ, Hettiaratchy S, Jeffery SL, Evriviades D, Kay AR. Contemporary approaches to definitive extremity reconstruction of military wounds. J R Army Med Corps 2009;155:302-7.

6. Çelikel A, Karaarslan B, Demirkıran DS, Zeren C, Arslan MM. A series of civilian fatalities during the war in Syria. Ulus Travma Acil Cerrahi Derg 2014;20:338-42.

7. Karakuş A, Yengil E, Akkücük S, Cevik C, Zeren C, Uruc V. The reflection of the Syrian civil war on the emergency department and assessment of hospital costs. Ulus Travma Acil Cerrahi Derg 2013;19:429-33.

8. Available at: http://www.news10.com. [Accessed: 8/10/2012].

9. Belmont PJ Jr, Thomas D, Goodman GP, Schoenfeld AJ, Zacchilli M, Burks R, et al. Combat musculoskeletal wounds in a US Army Brigade Combat Team during operation Iraqi Freedom. J Trauma 2011;71:E1-7.

10. Blair JA, Patzkowski JC, Schoenfeld AJ, Cross Rivera JD, Grenier ES, Lehman RA, et al. Are spine injuries sustained in battle truly different? Spine J 2012;12:824-9.

11. Cross JD, Ficke JR, Hsu JR, Masini BD, Wenke JC. Battlefield orthopaedic injuries cause the majority of long-term disabilities. J Am Acad Orthop Surg 2011;19:S1-7.

12. Dougherty PJ. Transtibial amputees from the Vietnam War. Twenty-eight-year follow-up. J Bone Joint Surg [Am] 2001;83:383-9.
13. Schoenfeld AJ. The history of combat orthopaedic surgery. In: Owens BD, Belmont PJ Jr, editors. Combat Orthopaedic Surgery: Lessons Learned in Iraq and Afghanistan. Thorofare, NJ: SLACK Incorporated; 2011. p. 3-12.

14. Stansbury LG, Lalliss SJ, Branstetter JG, Bagg MR, Holcomb JB. Amputations in U.S. military personnel in the current conflicts in Afghanistan and Iraq. J Orthop Trauma 2008;22:43-6.

15. Della Rocca GJ, Crist BD. External fixation versus conversion to intramedullary nailing for definitive management of closed fractures of the femoral and tibial shaft. J Am Acad Orthop Surg 2006;14:S131-5.

16. Tejwani NC, Polonet D, Wolinsky PR. External fixation of tibial fractures. Instr Course Lect 2015;64:185-9.

17. Mathieu L, Ouattara N, Poichotte A, Saint-Macari E, Barbier $\mathrm{O}$, Rongiéras $\mathrm{F}$, et al. Temporary and definitive external fixation of war injuries: use of a French dedicated fixator. Int Orthop 2014;38:1569-76.

18. Akpoto YM, Abalo A, Adam S, Sama HD, Dellanh YY, Amavi KA, et al. Extremity injuries in soldiers during the conflict in Mali: experience of Togo Level two Hospital. Int Orthop 2015;39:1895-9.

19. Penn-Barwell JG, Bennett PM, Fries CA, Kendrew JM, Midwinter MJ, Rickard RF. Severe open tibial fractures in combat trauma: management and preliminary outcomes. Bone Joint J 2013;95-B:101-5.

20. Awais S, Saeed A, Ch A. Use of external fixators for damage-control orthopaedics in natural disasters like the 2005 Pakistan earthquake. Int Orthop 2014;38:1563-8.

21. Alhammoud A, Maaz B, Alhaneedi GA, Alnouri M. External fixation for primary and definitive management of open long bone fractures: the Syrian war experience. Int Orthop 2019;43:2661-70.

22. Atik OŞ. Is there something new and interesting in my article? Eklem Hastalik Cerrahisi 2019;30:69.

23. Döner P, Ozkara A, Kahveci R. Syrian refugees in Turkey: numbers and emotions. Lancet 2013;382:764. 